\title{
Sustainable Development of Inter-Company Relations in the Context of Digitalization
}

\author{
Anna Tikhonova*, Dina Prostova, Natalya Sosnina \\ Ural State University of Economics, Ekaterinburg, Russia \\ "Corresponding author. Email: yami513@mail.ru
}

\begin{abstract}
The object of study in this research is the network potential of economic entities, and the subject is the sustainable development of inter-company interactions in terms of digitalization. Logical and system analyses were used as research methods. According to the authors, one of the key characteristics of economic entities in modern conditions will be the presence of such a potential that will provide them with the ability to ensure the creation and maintenance of effective inter-firm interactions. The purpose of the study is to develop a sequence of actions in managing the development of digitalization of inter-company interactions. The advantage of the scheme is the simplicity of its application, which is especially important for small and medium-sized economic entities that do not have specific resources to create effective inter-firm interactions and increase their stability. The scheme developed by the authors will allow economic entities to increase satisfaction from the created inter-company interactions and form the most effective strategies for their development.
\end{abstract}

Keywords: network potential, inter-company interactions, sustainability, development, digital economy, digitalization.

\section{INTRODUCTION}

The current stage of economic development is characterized by increased competition between economic entities for financial, material and intellectual resources (human capital), which is caused by the growth of their innovation and information activity. However, the developing digital economy does not allow us to consider competition as the main way of interaction in the market: from the economic point of view as well as social development of the country, it is necessary to consider in detail the dilemma of the relationship between the processes of competition and cooperation in the organization of inter-firm interactions. These features lead to the formation of new forms of organization of inter-company interactions based on the advantages of flexible structures, contracts and other types of agreements, the integration of external components into various types of network forms of organization and adaptation to rapidly changing market realities. Many experts recognize that it is the ability of economic entities to cooperate and manage joint activities for more efficient use of resources (including information), reducing uncertainty in the process of economic interaction and the introduction of technological, product and organizational innovations that leads to an increase in the competitiveness of organizations [1]. It confirms the theory by M. Castells [2] about the global processes taking place in the modern world under the influence of information technologies development, when information becomes the basis for the formation of a new economy. Innovative changes in technologies occur in parallel with economic and social changes, as rigid vertically integrated institutions are gradually replaced by flexible horizontal networks.

As mentioned above, at present, the conditions in which modern organizations have to carry out their activities are significantly different from classical practice. The process of economic integration, which are taking on a global character, cause an acceleration of changes and an increase in the degree of uncertainty at the meso - and macro-levels. In the conditions of the developing digital economy, new types of industries are emerging, in which specific knowledge, supported by the ability to use it, become key competencies and a prerequisite for successful activity. It leads to fundamental changes at the micro level: the relationships between economic entities change due to changes in the characteristics of the environment in which they interact. The nature of competition is changing. Competitive 
advantages are to be based largely on mutually beneficial relationships.

The key condition for the development of any organization is its ability to ensure its long-term effective functioning and its positive impact on the national economy. In order for the capabilities of a market entity to be realized into a powerful management resource, it is necessary to significantly increase the efficiency of its internal management. It requires the improvement of scientific and methodological tools as a system-forming element that expresses the actions of economic laws and forms the conditions for effective management, since, according to the authors; the mechanisms of managerial decision-making in many organizations are not effective enough in the light of modern trends in economic development.

\section{MATERIALS AND METHODS}

The object of study in this research is the network potential of economic entities, and the subject is the sustainable development of inter-company interactions in the conditions of digitalization. Logical and system analyses were used as research methods. The specifics of the determining factors problem that affect the ability of economic entities to build effective long-term intercompany interactions in the context of digital economy development determined the structure of this study.

The research algorithm included the following stages:

1) the study of scientific research reflected in the periodical press on the development, sustainability and inter-firm interactions in the conditions of digitalization;

2) the formation of the authors' vision of the economic entities network potential in the conditions of digitalization;

3) the development of actions sequence in managing the development of digitalization of inter-company interactions.

\section{RESULTS AND DISCUSSION}

It is important to note that the management of an organization development cannot be considered separately from the management of its activities as a whole. Within the framework of disparate management, contradictions may arise between the goals and objectives of various departments, therefore, a unified management and planning system based on a comprehensive assessment of the organization's activities is required.

In this regard, the authors analyzed the interpretations of the concept of "development" used in scientific Russian and foreign literature [3-5]. Two main approaches to the interpretation of the definition were identified:

1) Development is considered as a change in the object without taking into account the direction of this change.

2) Development is a process of qualitative transition of an object to a higher state.

The next stage of the analysis is the study of the term "stability". The main approaches to the interpretation of this term are shown in Figure 1.

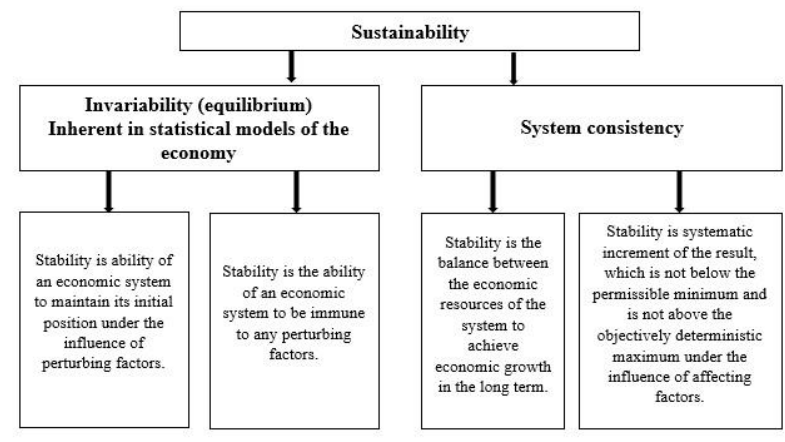

Figure 1 The term "stability" in various approaches [6$11]$

Therefore, the sustainable development of the organization is the process of purposeful formation of the organization's capabilities into a single system, taking into account the variability of the requirements of the external environment.

Next, it is necessary to determine the meaning of "digital economy" and "digitalization" in the content of this study. In general, the digital economy is the production of goods by the use of digital technologies.

The term "digitalization", which is closely related to the concept of the digital economy, can be designated as "the process of transition of an enterprise or an entire economic industry to new models of business processes, management and production methods based on information technologies" [12]. Digitalization also implies the existence of a single information space for the continuous exchange of data between various spheres of activity and structural divisions, which is achieved through a radical change in existing business models and the introduction of modern information technologies [13].

According to the authors, digitalization of intercompany interactions provides an increase in the effects of creating interactions due to the implementation of the following functions:

- collecting information from various management entities;

making the most appropriate management decisions; 
- providing information on the requests of participants in inter-company interactions.

The coordination of process and interactions is carried out on the basis of concluded agreements on information cooperation on the exchange of data on the scientific and technical reserve being formed and already created, production capacities, issues of the use and protection of information resources and the regulation of access to them.

According to the authors, one of the key characteristics of economic entities in modern conditions will be the presence of such a potential that will provide them with the ability to ensure the creation and maintenance of effective network inter-firm interactions. In this regard, this paper proposes to consider the economic category "network potential of a firm" as "a set of means and opportunities for creating inter-firm interactions in order to increase their effectiveness in the conditions of the development of the digital economy". In general, the network potential characterizes the opportunities available to an economic entity and allows us to determine those opportunities that it does not have for expanding inter-firm interactions and increasing their stability.

The contextual tasks of managing the development of digitalization of inter-company interactions, thus, can be reduced to the following set of measures to change the network potential.

First, it is the identification of leading information and communication technologies that determine the organization's ability to implement the development of inter-company interactions. The contradiction between" digitalization " and the strategy of behavior arises if the organization's strategy implies using the available information and communication resource only for the purpose of increasing productivity and strengthening competitiveness, without directing the existing abilities and not using the opportunities, for example, for creating cluster structures, including in value creation networks, etc. Second, it is the formation of a mechanism for cyclical redistribution of intra-organizational resources to ensure the sustainable development of inter-company interactions. In this case, the organization due to a place in the value chain (network), for example, will receive resource support from supplier enterprises, manufacturing enterprises and other stakeholders, which will ensure, accordingly, an increase in efficiency. A weak level of digitalization will not allow us to develop the commercialization of scientific developments by increasing the demand for them. The formation and development of research clusters will also be difficult.

Thirdly, it implies ensuring the normal operation of direct and reverse communication channels. Since the control system reduces its effectiveness when the bandwidth of the impact channels is disrupted or the control actions are deformed in them, the organization's development strategy should ensure the variability of impacts on the forms of interactions between the elements of the organization in order to improve the resource and information exchange between them. It implies the formation of network potential in terms of directing efforts to develop cooperation institutions that would contribute to increasing trust and information openness. It will lead to the emergence of new ideas and projects, more efficient use of organizational resources, solving common problems of the organization and its components, forming the necessary ways to coordinate the development strategy.

In addition, digitalization should facilitate the establishment of closer ties between all actors interested in interaction. As a result, the implementation of managerial influences should lead to changes within the structure of the organization as a whole, its movement towards improving the efficiency of inter-firm interactions.

\section{CONCLUSION}

The management of digitalization development within the inter-company interactions should be carried out in accordance with a certain list of consistently performed organizational steps presented in Figure 2.

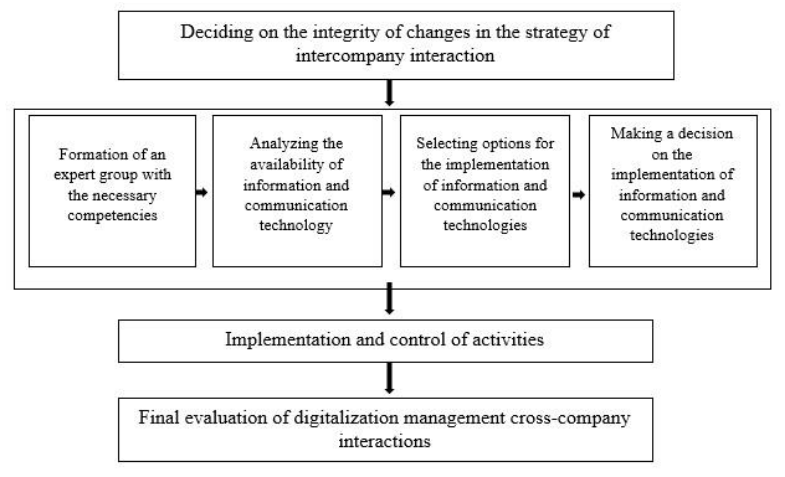

Figure 2 The sequence of actions in managing the development of digitalization of inter-company interactions

The advantage of the scheme is the simplicity of its application, which is especially important for small and medium-sized economic entities that do not have specific resources to create effective inter-firm interactions and increase their stability.

The approach formulated by the authors can be implemented according to the generalized scheme for determining the priority digitalization directions of intercompany interactions, shown in Figure 3. 


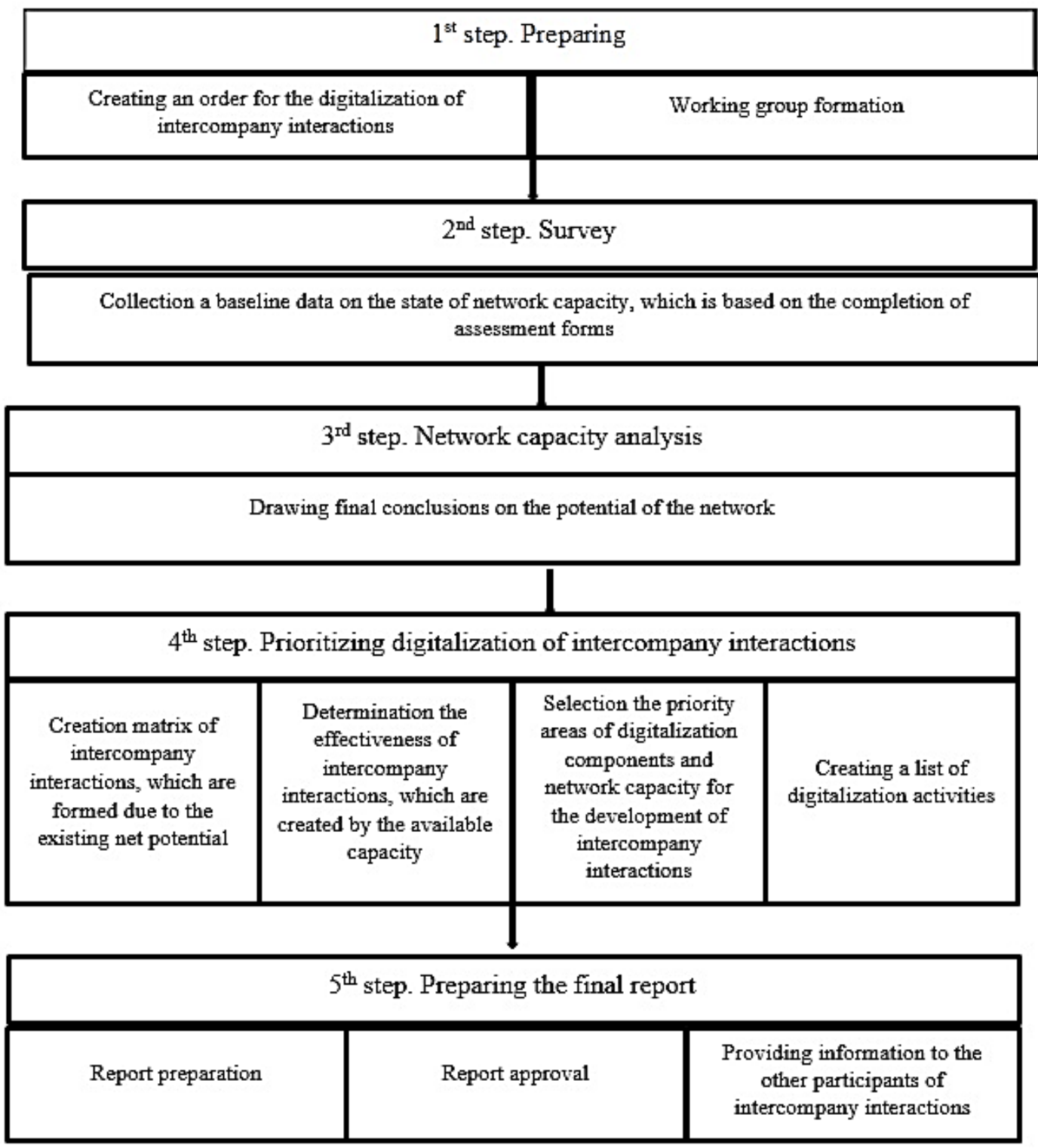

Figure 3 The scheme of determining the priority digitalization directions of inter-company interactions

It is advisable to build a roadmap for transformations in any socio-economic system (including in the system of inter-firm interactions) on the basis of the DemingShewhart cycle, which, in relation to the implementation of information and communication technologies, will include the following main stages of transformation:

1. Audit of available information and communication technologies. Revealing ineffective "outdated" information processing mechanisms; as well as technologies that are not available for fully effective interactions.

2. Description of the implementation of information and communication technologies to increase the speed of information circulation and, as a result, to increase the efficiency of inter-firm interactions.
3. Development of a plan for the introduction of technologies that provide a unified information and communication infrastructure.

4. Introduction of information and communication technologies.

5. The closing stage is the control of the implementation of information and communication technologies and the assessment of the results obtained.

The scheme developed by the authors will allow economic entities to increase satisfaction from the created inter-company interactions and form the most effective strategies for their development. 


\section{REFERENCES}

[1] E. V. Popov, V. L. Simonova, M. A. Maksimchik, Assessment of network potential on the example of IT-industry. Economic Analysis: Theory and Practice, 17(10) (2018) pp. 1819-1834. DOI: https://doi.org/10.24891/ea.17.10.1819

[2] M. Castells, The Information Age: Economy, Society and Culture, UK: Blackwell, 1996.

[3] N. T. Agafonova, P. A. Islyaev, The main provisions of the draft concept of the transition of the Russian Federation to a model of sustainable development, Economics. Entrepreneurship. Environment, 1-2 (1995) pp. 47-52.

[4] O. A. Aleshkina, Globalization of Education and the Innovative Mechanism for the Development of Russian Universities Proceedings of the Russian State Pedagogical University, 24 (2008) pp. 11-14.

[5] Y.S. Alferov, Monitoring Educational Development in the World, Pedagogy, 7 (2002) pp. 88-95.

[6] N. R. Kelchevskaya, Assessing the economic sustainability of a state university, University Management, 4(23) (2002) pp. 5-23.

[7] V.G. Lebedev, Methods for assessing the stability of functioning and development of the industrial enterprise and ways out of the crisis situation, ed. by G.A. Krayukhin: monograph, SPb:SPbGIEU, 2010.

[8] Yu. V. Sirotova, Stability of enterprise development in the transitional economy: thesis of Candidate of Economic Sciences, Moscow, 2009, pp. 195.

[9] A. G. Granberg, V. I. Danilov-Danilyan, M. M. Tsikanov, E. S. Shopkhoev, Strategy and Problems of Russia's Sustainable Development in the XXI Century, M.: Economics, 2002, pp. 414.

[10] A. D. Ursul, Conceptual problems of sustainable development, Bulletin of the Russian Academy of Sciences. Use and protection of natural resources in Russia, 1 (2005) pp. 30-38.

[11] V. K. Chertykovtsev, A. N. Bogusonov, Bulletin of Saratov State Socio-Economic University, 2006.

[12] Business \& Information Technology, http://bit.samag.ru/uart/more/67

[13] A. Vichugova, Digitalization and automation - not the same thing: 5 main differences, https://www.bigdataschool.ru/blog/\%D1\%86\%D0 $\%$ B8\%D1\%84\%D1\%80\%D0\%BE\%D0\%B2\%D0 $\%$ B8\%D0\%B7\%D0\%B0\%D1\%86\%D0\%B8\%D1 $\% 8 \mathrm{~F}-\% \mathrm{D} 0 \% \mathrm{~B} 8-\% \mathrm{D} 0 \% \mathrm{~B} 0 \% \mathrm{D} 0 \% \mathrm{~B} 2 \% \mathrm{D} 1 \% 82 \% \mathrm{D} 0$ $\% \mathrm{BE} \% \mathrm{D} 0 \% \mathrm{BC} \% \mathrm{D} 0 \% \mathrm{~B} 0 \% \mathrm{D} 1 \% 82 \% \mathrm{D} 0 \% \mathrm{~B} 8 \% \mathrm{D} 0$ $\% \mathrm{~B} 7 \% \mathrm{D} 0 \% \mathrm{~B} 0 \% \mathrm{D} 1 \% 86 \% \mathrm{D} 0 \% \mathrm{~B} 8 \% \mathrm{D} 1 \% 8 \mathrm{~F} . \mathrm{html}$ 